DOI: http://dx.doi.org/10.22483/2177-5796.2017v19n3p711-733

\title{
Visão atual das pesquisas nacionais sobre afetividade e ensino de física
}

\author{
Cleci Teresinha Werner da Rosa \\ Luiz Marcelo Darroz \\ Ana Claudia Tasso dos Santos
}

\begin{abstract}
Resumo: O presente estudo tem como objetivo mapear o estado atual das investigações em afetividade e ensino de Física, para identificar os focos de interesse e apontar questões para futuras pesquisas. Ao total, foram investigados 3.508 artigos, e resultados da análise indicaram a existência de nove artigos sobre a temática afetividade e ensino de Física, que foram considerados objetos de estudo. Depois de lidos e analisados, os artigos foram estruturados em categorias. Dessa análise, constatou-se que há um reduzido número de estudos na temática e que a prioridade está em investigações no campo da motivação e emoção. Os resultados suscitam investigações futuras referentes à produção internacional e inferem a necessidade de realizar estudos, considerando aspectos como atitudes, atribuição e confiança em si mesmo em relação ao ensino de Física.
\end{abstract}

Palavras-chave: Afetividade. Ensino de Física. Estado da arte.

\section{Researches current view national on affectivity and the Physics teaching}

\begin{abstract}
This study aims to map the current state of investigations on affection and Physics teaching, in order to identify the focuses of interest and point out questions for future researches. In total, 3508 articles were investigated the results of the analysis indicated the existence of nine articles on the topic of affection and Physics teaching, which were considered study objects. After read and analyzed, the articles were structured in categories. This analysis showed there is a reduced number of studies on the topic and that investigations on the field of motivation and emotion are prioritized. The results evoke further investigations regarding the international production and infer the need for studies that consider aspects such as attitude, attribution, and self-confidence related to Physics teaching.
\end{abstract}

Keywords: Affectivity. Physics teaching. State of art.

Quaestio, Sorocaba, SP, v. 19, n. 3, p. 711-733, dez. 2017. 


\section{Introdução}

O reconhecimento de que a aprendizagem mobiliza afetos, emoções e relações com seus pares, além das cognições e habilidades intelectuais, é tido pelos Parâmetros Curriculares Nacionais (PCN) como um dos pressupostos sob os quais a organização curricular do Ensino Médio deve ser orientada (BRASIL, 2002). No documento fica explícita a necessidade de lidar com sentimentos associados às situações de aprendizagem, uma vez que tais sentimentos influenciam a relação do aluno com o conhecimento. Nas palavras do documento tem-se que: "reconhecer que as situações de aprendizagem provocam também sentimentos e requerem trabalhar a afetividade do aluno" (p. 102).

Entretanto, tal relação cognição-afeto nem sempre esteve assegurada, pois a psicologia tradicional sempre se preocupou em estudar o funcionamento psicológico (cognitivo) de forma fragmentada, isolando desse processo a dimensão afetiva e negligenciando-a enquanto substrato da constituição do homem. Foi necessário emergir a psicologia cognitiva no século XX para superar essa dicotomia e apontar na direção da indissociabilidade entre afeto e cognição nos mecanismos de construção do saber. Autores clássicos como Jean Piaget, Henri Wallon e Lev S. Vygotsky, por exemplo, enfatizam o vínculo entre cognição e afeto como constituinte do processo de aprendizagem.

O realce dado à dimensão afetiva pelos pesquisadores da psicologia cognitiva, especialmente em termos de sua importância no contexto escolar, tem recebido mais atenção quando se trata da sua presença e influência nos anos iniciais do processo de escolarização. Tal percepção decore do entendimento de que a dimensão cognitiva vincula-se ao afeto, sendo a emoção:

a condição indispensável para o ingresso no mundo da razão e da competência humana, na medida em que possibilita uma primeira forma de comunicação, básica, primitiva, profunda, lastro sobre o qual se construirá a comunicação linguística que transporta o conhecimento e dá ingresso à vida cognitiva (PINTO, 1993, p. 73).

$\mathrm{Na}$ atualidade, a influência da afetividade na aprendizagem tem se estendido aos diferentes níveis escolares e associado às distintas componentes curriculares. Como efeito, temos um entendimento mais amplo e específico para a dimensão afetiva na qual estão presentes e influenciando a aprendizagem escolar, questões como motivação, autoestima, emoções, entre outras. E nesse contexto emergem trabalhos que buscam essa aproximação com as 
especificidades de cada campo do conhecimento. No caso do ensino de Matemática e que pode ser estendido ao campo das Ciências, surgem estudos como os desenvolvidos por Lafortune e Saint-Pierre (1996) voltados a investigar a influência dessa dimensão na apropriação dos saberes. As autoras, preocupadas com o pouco sucesso dos alunos na aprendizagem em Matemática, inferem a dimensão afetiva como algo a ser considerado pelos professores no planejamento de suas aulas:

Pela experiência prática do ensino, os professores sabem que as aptidões intelectuais não são os únicos factores em causa no sucesso escolar [...] eles estão conscientes de que os factores afetivos e metacognitivos, em relação aos quais o seu papel lhes parece difícil de definir, adquirem uma importância primordial no insucesso ou sucesso (LAFORTUNE; SAINT-PIERRE, 1996, p. 17).

Estendendo-se o exposto pelas autoras a disciplina de Ciências (Física) e limitando-se a analisar a influência da dimensão afetiva, destaca-se o trabalho de Maurina (2008) que reflete sobre a influência das expectativas dos estudantes sobre o processo de ensino e de aprendizagem em Física. A autora divide as expectativas em positivas e negativas, destacando as que podem apresentar um caráter obstante ao processo de ensino e de aprendizagem, e as expectativas que são passíveis de controle pelo professor.

As dificuldades dos estudantes em se apropriar do conhecimento, fato que não se restringe a Física, Ciências ou Matemática, mas que permeia outras disciplinas escolares, podem estar associadas à falta de sintonia entre os conteúdos abordados na escola e os desejos e anseios dos estudantes, especialmente os vinculados aos fatores afetivos (LAFORTUNE; SAINT-PIERRE, 1996). No campo da Física especificamente, questões vinculadas à falta de motivação ou desinteresse pelo conteúdo têm sido anunciadas como justificativas para o baixo rendimento dos alunos. O sentimento positivo em relação à disciplina colabora para a aprendizagem e para que os alunos se aproximem da Física. Por outro lado, os bloqueios emocionais e sentimentos negativos muitas vezes provocados pela forma como os conteúdos são discutidos no contexto da sala de aula contribuem para o repúdio que muitos alunos têm em relação à Física.

A importância do tema, e o quanto ele precisa ser aprofundado e debatido pelos professores e pesquisadores da área, foi anunciada por Rezende e Ostermann (2005) ao desenvolverem um estudo com objetivo de 
trazer novos elementos para a reflexão sobre a relação entre os resultados da pesquisa acadêmica e a prática do professor, propondo o confrontamento entre problemas da prática pedagógica do professor de física com o que a pesquisa em ensino-aprendizagem de física tem proporcionado nos últimos anos (p. 319).

Neste estudo que envolveu a produção nacional no período de 2000 a 2004 em atas de eventos e periódicos, as autoras identificam discrepâncias entre os dois contextos e também apontam a necessidade de estabelecer e incluir a dimensão afetiva como novo objetivo de investigação, uma vez que ela tem se mostrado presente e influenciado o ensino de Física.

O estudo mencionado revela uma realidade vivenciada na literatura nacional há mais de dez anos, e tais resultados podem ter repercutido nas investigações realizadas a partir de então. Tal hipótese, juntamente com a relevância anunciada nos parágrafos anteriores pertinente a importância da dimensão afetiva como recurso favorecedor da aprendizagem dos conteúdos em Física, aponta para os seguintes questionamentos a que se pretende buscar respostas no presente estudo: a produção científica nacional tem revelado uma preocupação com a associação da dimensão afetiva com o ensino de Física? O modo como tal dimensão tem sido considerada nesses estudos expressa resultados que permitem inferir sobre a sua eficácia na apropriação dos conteúdos de Física?

Os questionamentos delineados para esse estudo definem como objetivo principal realizar uma investigação do tipo estado da arte, junto aos periódicos nacionais como forma de identificar os estudos envolvendo o tema afetividade associados a Ciências/Física nos diferentes graus de ensino. Como recorte é definido os periódicos nacionais da Área de Ensino estrato A1, A2 e B1 no sistema web Qualis 2014.

Julga-se oportuno visitar a produção na temática afetividade como forma de examinar o corpus de estudos publicados nos últimos dez anos, com intuito de mapear as recentes produções na área, identificando possíveis padrões e tendências emergentes nesses estudos. Especificamente, tal pesquisa permitirá examinar quais são os contextos científicos e conceituais envolvidos nas pesquisas, quais os aspectos da afetividade estão sendo estudados e que métodos são usados para investigar a temática.

Para responder aos questionamentos mencionados e ao objetivo apresentado, o presente trabalho foi estruturado de modo a, inicialmente, discorrer sobre o entendimento do termo afetividade e das componentes definidas como integrantes dessa dimensão na voz de autores da 
área; na continuidade, apresenta-se a pesquisa realizada no estudo de modo descrever seus aspectos metodológicos e o recorte feito no estudo, bem como apresentar as tabelas com os dados coletados e sua distribuição em função da frequência; a seguir, apresentam-se as discussões dos resultados do estudo a partir de categorias pré-estabelecidas; por fim, têm-se as considerações finais abordando os principais aspectos do estudo e a possibilidade de novas investigações decorrentes do apresentado.

\section{$O$ entendimento de afetividade}

A consideração da dimensão afetiva como elemento integrante de atividades que envolvem a razão é recente. Praticamente até o século XX existia uma dicotomia entre razão e emoção, estando a primeira vinculada à mente, e a segunda, ao corpo. Acreditava-se que os aspectos afetivos "turvavam" a visão clara da razão, ou seja, o conhecimento verdadeiro só seria atingido racionalmente, necessitando para isso afastar os sentimentos (PINHEIRO, 2003; SANTOS, 1996).

Compreende-se, entretanto, que por mais racionais que sejam os conhecimentos elaborados pela ciência, o ensino de Física e de Ciências é regulado por relações afetivas entre os vários agentes do ato educacional. Dessa forma, visando esclarecer esses aspectos, será apresentada uma argumentação que pretende sobrepujar as relações clássicas estabelecidas entre razão e afeto, para, a partir disso, anunciar o entendimento do termo afetividade que subsidia as investigações deste trabalho.

A histórica separação entre corpo e mente, razão e emoção, tem origem no pensamento grego. Segundo o entendimento das ideias platônicas, razão e emoção situam-se em mundos diferentes. A razão, pertencente ao mundo das ideias, estaria estabelecida na alma e relacionada à cabeça. As emoções, provenientes dos sentidos, estariam localizadas no corpo. No panorama da teoria das ideias, o conhecimento verdadeiro só poderia ser alcançado através da razão, sendo considerado impreciso o conhecimento advindo dos sentidos. Nessa visão, o conhecimento seguro deve ser racional e livre de sentimentos (PINHEIRO, 2003). Essa dicotomia entre razão e emoção influenciou vários aspectos da vida, inclusive a atividade científica. A noção de que o conhecimento científico, aparentemente, é produzido na 'mais pura cognição' e livre de 
sentimentos, atingiu o campo educacional, de modo que a aprendizagem de ciências tem sido apresentada desarticulada dessa dimensão.

Um marco da discussão sobre a relação entre razão e sentimento ocorreu em 1890, quando William James postulou a existência de um mecanismo básico que, quando recebe estímulos do meio ambiente provocam um padrão específico de reações no corpo (DAMÁSIO, 1996). Segundo Pinheiro (2003), uma ligação mais estreita entre emoção e razão é proposta por John Dewey em 1895, "ao colocar a experiência emocional no centro do comportamento racional, acreditando que a emoção é produto da racionalidade” (p. 50).

O trabalho de António Damásio, no ramo da Neurociência, dá prosseguimento a essa linha de pensamento com a obra $O$ erro de Descartes: emoção, razão e cérebro humano. Para o autor, as emoções e os sentimentos "servem de guias internos e ajudam-nos a comunicar aos outros sinais que também os podem guiar. E os sentimentos não são nem intangíveis nem ilusórios. Ao contrário da opinião científica tradicional, são precisamente tão cognitivos como qualquer outra percepção" (1996, p. 15).

Outras teorias têm influenciado as reflexões sobre o processo de ensino e aprendizagem. Jean Piaget considera que o afeto cumpre um papel importante no funcionamento da inteligência e que a afetividade precede as funções cognitivas, interferindo e sendo interferida pelas mesmas. Piaget ressalta também que dificuldades no aprendizado estão relacionadas com bloqueios de ordem afetiva. Lev S. Vygotsky direciona suas ideias em defesa da estreita ligação entre a dimensão afetiva e a cognitiva, afirmando que a afetividade guia a atividade do estudante, visto que o pensamento é originado no âmbito da motivação (constituída por afeto, emoção, necessidades, interesses e inclinações) e que em cada ideia da realidade existe uma atitude afetiva que se modificou (PINHEIRO, 2003).

Para Vygotsky (1995), uma compreensão integral do pensamento humano só é possível quando se entende sua base afetiva, porque

\footnotetext{
a separação entre intelecto e afeto enquanto objetos de estudo é uma das principais deficiências da psicologia tradicional, uma vez que esta apresenta o processo de pensamento como um fluxo autônomo de "pensamentos que pensam a si próprios", dissociado da plenitude da vida, das necessidades e dos interesses pessoais, das inclinações e dos impulsos daquele que pensa (p. 6).
}

Quaestio, Sorocaba, SP, v. 19, n. 3, p. 711-733, dez. 2017. 
As emoções, para Henri Wallon, têm papel determinante no desenvolvimento da pessoa. Bessa (2008), versando sobre o afeto no processo e tendo como referencial a aprendizagem na teoria de Wallon (1949), destaca que,

para a criança, o afeto é importantíssimo. Ela precisa se sentir segura para poder desenvolver seu aprendizado. Para que esse processo ocorra de forma significativa, o professor precisa ter consciência dos seus atos em relação aos alunos, uma vez que as emoções também fazem parte desse processo, estruturando a inteligência do indivíduo (p. 76).

Um processo de revisão da dicotomia entre razão e emoção que se desenvolveu inicialmente no campo da Psicologia e da Neurociência permeou outras áreas, como a educação. O campo educacional tem recebido um tratamento mais completo e integrador ao incluir aspectos emocionais e afetivos nos processos cognitivos.

Nessa maior ampliação frente ao domínio afetivo, autores como Gómez Chacón (2003) apontam que a falta de clareza do termo "afetividade" é um dos problemas na compreensão da sua potencialidade no ensino e na aprendizagem, fato que é perceptível ao percorrer alguns referenciais bibliográficos, uma vez que há autores que associam os domínios afetivos a atitudes, crenças, considerações, gostos e preferências, emoções, sentimentos e valores. Entretanto, outros buscam vinculá-los a termos mais gerais, como os sentimentos e o humor. Particularmente, a autora chama a atenção para a sua opção, na qual acrescenta aos sentimentos e as emoções, aspectos como as crenças, as atitudes, os valores e as considerações (GÓMEZ CHACÓN, 2003).

Pinheiro (2003), por sua vez, menciona que: "uma referência que é considerada um marco para as pesquisas em ensino que abordam a afetividade é o trabalho de Martin e Briggs (1986)" (p. 53). Lafortune e Saint-Pierre (1996), apoiando-se igualmente no estudo, de Martin e Briggs lembram que para as autoras a afetividade é integralizada pelas componentes atitude, emoção, motivação e atribuição. A elas, Lafortune e Saint-Pierre (1996) incluem a componente confiança em si mesmo, considerando a importância desses aspectos no processo de aprendizagem. E nesse entendimento de Lafortune e Saint-Pierre (1996) que o presente estudo se situa, uma vez que o objetivo está em verificar a forma como os estudos vêm considerando esta dimensão na área de ensino de Física/Ciências. A opção decorre do fato dessas autoras ampliarem e aprofundarem os elementos da dimensão afetiva propostos por Martin e Briggs, que são considerados um marco para as pesquisas envolvendo a dimensão afetiva. 
A seguir são detalhados cada um desses componentes seguindo o anunciado por Lafortune e Saint-Pierre (1995) e que constituirão as categorias de análise dos dados coletados na presente pesquisa.

As atitudes, para Lafortune e Saint-Pierre (1995), apoiando-se em Legendre (1993), estão relacionadas com "um estado de espírito" que uma pessoa adquire sobre si e/ou de algum elemento externo, como uma pessoa ou um evento, que incentiva a forma de estar ou de agir favorável ou desfavorável. Ou seja, basicamente, são as posturas adotadas diante de uma determinada situação. No contexto escolar, a imagem que o estudante tem sobre a disciplina pode interferir no seu comportamento diante dela, como também pode influenciar a escolha de sua carreira (PINHEIRO, 2003).

A atribuição consiste na interpretação que uma pessoa faz das causas de um evento. Segundo Lafortune e Saint-Pierre (1996, p. 36), "uma atribuição é interna se depender da pessoa envolvida e externa se não depender da pessoa". A atribuição pode determinar a atitude de uma pessoa diante de uma situação. Alunos que atribuem seus sucessos e/ou fracassos a causas internas tendem a perseverar mais nas atividades escolares do que aqueles que justificam seus sucessos e/ou fracassos a causas externas (LAFORTUNE; SAINT-PIERRE, 1996). Por outro lado, professores que atribuem "o bom desempenho de seus alunos unicamente ao talento dos mesmos, dificilmente adotará estratégias diferenciadas para tentar superar as dificuldades de aprendizagem" (PINHEIRO, 2003, p. 58).

A confiança em si mesmo é um conceito relacionado à autoestima, onde o indivíduo cria uma representação de si próprio em relação à sua capacidade de executar uma tarefa. Um estudante pouco confiante tende a desistir diante da menor dificuldade. Lafortune e Saint-Pierre (1996) afirmam que a confiança é condição para o aluno continuar na busca de soluções, apesar das dificuldades. Além disso, as autoras reconhecem que uma experiência de sucesso pode ajudar a sustentar ou aumentar a autoconfiança do estudante. O trabalho do professor também sofre influência dessa componente. O docente tenderá a fazer uso dos métodos e estratégias de ensino que sente maior confiança, procurando evitar aqueles em que se sente mais inseguro. Exemplos típicos desse aspecto no ensino de Física e de ciências são as atividades de laboratório (PINHEIRO, 2003) e a prática da interdisciplinaridade (KLEIMAN; MORAES, 1999).

A definição de emoções para Lafortune e Saint-Pierre (1996, p. 32), embasada em autores como Sillamy (1980) e Martin e Briggs (1986), é "uma reação afetiva que se manifesta de 
diferentes maneiras, como medo, raiva, alegria, tristeza, desgosto, angústia, prazer, ansiedade, as quais podem ser identificadas diante de algumas atividades de aprendizagem”. Damásio (1996, 2000) discute três níveis de emoção: primário, secundário e de fundo. As emoções primárias compreendem alegria, tristeza, medo, raiva, surpresa e repugnância; as secundárias incluem embaraço, ciúme, culpa e orgulho; as de fundo abarcam bem-estar, mal-estar, calma, tensão, irritação, desânimo, entusiasmo, abatimento e animação. A partir de estudos com indivíduos com lesões neurológicas, Damásio (1996) indica que uma redução seletiva da emoção é tão prejudicial para a racionalidade quanto a emoção excessiva. Casos clínicos narrados em Sacks (1995) revelam como toda a base afetiva da vida pode ser podada por uma lesão neurológica. Como exemplo, temos o caso de um juiz que sofreu uma lesão no lobo frontal,

em consequência de fragmentos de uma granada no cérebro e, por conseguinte, viu-se totalmente desprovido de emoção. Poder-se-ia pensar que a falta de emoção, e as propensões que a acompanham, o tornariam mais imparcial - um juiz sem igual. Mas ele mesmo, com grande discernimento, renunciou ao cargo, alegando não poder mais entender com compaixão os motivos de alguém preocupado e que, já que a Justiça envolvia o sentimento e não apenas o pensamento, sua lesão o desqualificava totalmente para o cargo (p. 292).

A motivação é um conjunto de desejos e vontades que uma pessoa possui para cumprir uma atividade ou atingir um objetivo, que corresponde a uma necessidade ou interesse (LEGENDRE, 1993 apud LAFORTUNE; SAINT-PIERRE, 1996), determinando, geralmente, a conduta da pessoa diante de uma situação. Investigada sobre diversos enfoques teóricos, a motivação releva toda sua complexidade e constata a crescente preocupação em se entender a influência dos seus aspectos no processo de aprendizagem. A motivação é tradicionalmente diferenciada em intrínseca e extrínseca. A primeira é caracterizada pelo interesse e satisfação na atividade em si, isto é, depende da própria pessoa, podendo ser também estimulada pelos fatores externos e provoca, em longo prazo, resultados mais profundos e mais duradouros. Enquanto que a segunda visa à obtenção de recompensas, como o reconhecimento, ou escapar de punições e sanções, ou seja, é relacionada a ações realizadas em resposta a fatores externos ao sujeito, produzindo resultados imediatos mais impressionantes do que a motivação intrínseca (LAFORTUNE; SAINT-PIERRE, 1996). Uma teoria que tem trazido contribuições para o entendimento da motivação é Teoria de Metas de Realização, focando em um aspecto qualitativo do envolvimento do aluno, sendo representada pelas diversas formas de encarar as atividades escolares. Um aluno orientado à meta aprender, busca crescimento intelectual, mesmo que não 
sinta prazer nas atividades ou interesse pessoal nelas. Ter a preocupação de aparecer, de ser o melhor, caracteriza a meta performance (FERREIRA, 2012). Com relação à aprendizagem, Wlodkowski (1985 apud PINHEIRO, 2003, p. 61) afirma que

\begin{abstract}
as pessoas são sempre motivadas por alguma coisa, mas nem sempre estão motivadas para aprender. Como a motivação é pessoal, não é possível motivar alguém diretamente, mas pode-se apresentar coisas e situações atraentes e estimulantes que façam com que a pessoa passe a se sentir motivada. Assim, qualquer coisa a ser aprendida, pode ser apresentada de uma maneira motivadora. Por esta razão, este autor recomenda que todo programa de ensino deva incluir um programa de motivação.
\end{abstract}

As componentes da dimensão afetiva apresentada neste texto a partir dos estudos de Lafortune e Saint-Pierre $(1995,1996)$ não representam uma unanimidade na literatura especializada. O trabalho de Gómez Chacón (2003), cujo enfoque são as atividades de resolução de problemas, tem tanta importância quando o de Lafortune e Saint-Pierre, que visa uma melhor apropriação de conhecimentos e o desenvolvimento de habilidades afetivas. No entanto, optamos pela definição de domínio afetivo apresentado pelas autoras porque consideramos que suas componentes se aproximam mais do processo ensino e aprendizagem de Física, pelo seu trabalho estar mais vinculado à aprendizagem. Além disso, essas autoras apresentam maior tradição na pesquisa relacionada à afetividade.

\title{
Pesquisa
}

Para atingir os objetivos traçados e responder a pergunta central dessa investigação, adota-se uma investigação do tipo qualitativa, de natureza bibliográfica. A abordagem qualitativa, de acordo com Gil (1994), considera que existe uma relação entre o mundo e o sujeito que não pode ser traduzida em números, a pesquisa é considerada descritiva e o pesquisador tende a analisar seus dados indutivamente. Por bibliográfica o autor define como aquela pesquisa que busca dados em material já publicado, impresso ou disponibilizado pela Internet. Qualquer trabalho científico inicia-se com uma pesquisa bibliográfica, que permite a identificação do estágio atual do conhecimento referente ao tema (GIL, 2010).

E, ainda, por se tratar de uma pesquisa do tipo estado da arte, recorre-se ao mencionado por Romanowski (2002), em termos dos procedimentos para seleção do material, a saber: definição dos descritores que direcionam as buscas a serem realizadas; localização dos bancos de pesquisas; estabelecimento de critérios para a seleção do material; levantamento de material a ser 
catalogado; coleta desse material; leitura das publicações relacionadas ao tema; organização do material escrito sobre o estudo e, análise e elaboração das conclusões do estudo.

A partir desses referenciais de pesquisa e considerando o apontado por Romanowski (2002), o presente estudo estabeleceu como banco de dados da pesquisa, os periódicos nacionais na Área de Ensino relacionados à Física/Ciências disponíveis online, estratos A1, A2 e B1 no sistema webqualis da Coordenação de Aperfeiçoamento de Pessoal de Nível Superior (Capes), base de dados 2014. Ainda considerando os aspectos anunciados pelo autor, o estudo estabelece como recorte a produção compreendida entre 2006 e 2015. Para a busca nos periódicos adotou-se a metodologia de leitura do título, das palavras-chave e do resumo, tendo como critério para seleção do artigo a identificação dos seguintes termos: "afetividade", "atitude", "motivação", "confiança", "interesse", "emoções", "autoestima", "atribuição", seguindo o proposto na literatura pertinente e selecionada como referencial deste estudo.

Nesses periódicos, e considerando os descritores mencionados, encontrou-se um total de dezessete artigos. Após a leitura nesses artigos realizadas de forma individualizada por cada um dos autores do artigo, identificou-se que em oito deles não havia relação com os propósitos do estudo. Ou seja, oito artigos não tratavam a temática afetividade vinculada ao ensino de Física.

O Quadro 1 ilustra os periódicos analisados, o número de artigos presentes em cada periódico no período selecionado para a investigação e número de artigos identificados com o objetivo do presente estudo. 
Quadro 1 - Relação dos periódicos e artigos analisados

\begin{tabular}{|c|c|c|c|c|}
\hline Qualis & Periódico & $\begin{array}{l}\text { Total de } \\
\text { artigos }\end{array}$ & $\begin{array}{c}\text { Artigos } \\
\text { relacionados à } \\
\text { Física }\end{array}$ & $\begin{array}{c}\text { Artigos } \\
\text { relacionados } \\
\text { ao tema }\end{array}$ \\
\hline A1 & Ciência \& Educação & 475 & 65 & 1 \\
\hline A1 & Revista Brasileira de Ensino de Física & 791 & 791 & -- \\
\hline A2 & $\begin{array}{l}\text { Ensaio: Pesquisa em Educação em } \\
\text { Ciências }\end{array}$ & 288 & 57 & 3 \\
\hline A2 & $\begin{array}{l}\text { Revista Investigações em Ensino de } \\
\text { Ciências }\end{array}$ & 265 & 65 & 1 \\
\hline $\mathbf{A 2}$ & $\begin{array}{l}\text { Revista Brasileira de Pesquisa em } \\
\text { Educação em Ciências }\end{array}$ & 185 & 71 & 1 \\
\hline B1 & $\begin{array}{l}\text { Alexandria: Revista de Educação em } \\
\text { Ciências e Tecnologia }\end{array}$ & 196 & 309 & 1 \\
\hline B1 & Caderno Brasileiro de Ensino de Física & 309 & 21 & 1 \\
\hline B1 & Ciência \& Ensino & 62 & 19 & -- \\
\hline B1 & Revista Ciência em Tela & 114 & 12 & -- \\
\hline B1 & $\begin{array}{l}\text { Revista Experiências em Ensino de } \\
\text { Ciências }\end{array}$ & 265 & 85 & -- \\
\hline B1 & $\begin{array}{l}\text { Revista Brasileira de Ensino de Ciência e } \\
\text { Tecnologia }\end{array}$ & 205 & 28 & 1 \\
\hline B1 & Revista Ciências \& Ideias & 89 & 14 & -- \\
\hline B1 & Acta Scientiae & 264 & 18 & -- \\
\hline & Total & 3508 & 1555 & 9 \\
\hline
\end{tabular}

Fonte: Elaborado pelos autores, dados da pesquisa, 2016.

A Figura 1 apresenta o gráfico da distribuição dos artigos por ano, possibilitando analisar o interesse dos pesquisadores pela temática nos últimos dez anos.

Figura 1 - Gráfico dos estudos por ano entre 2006-2015

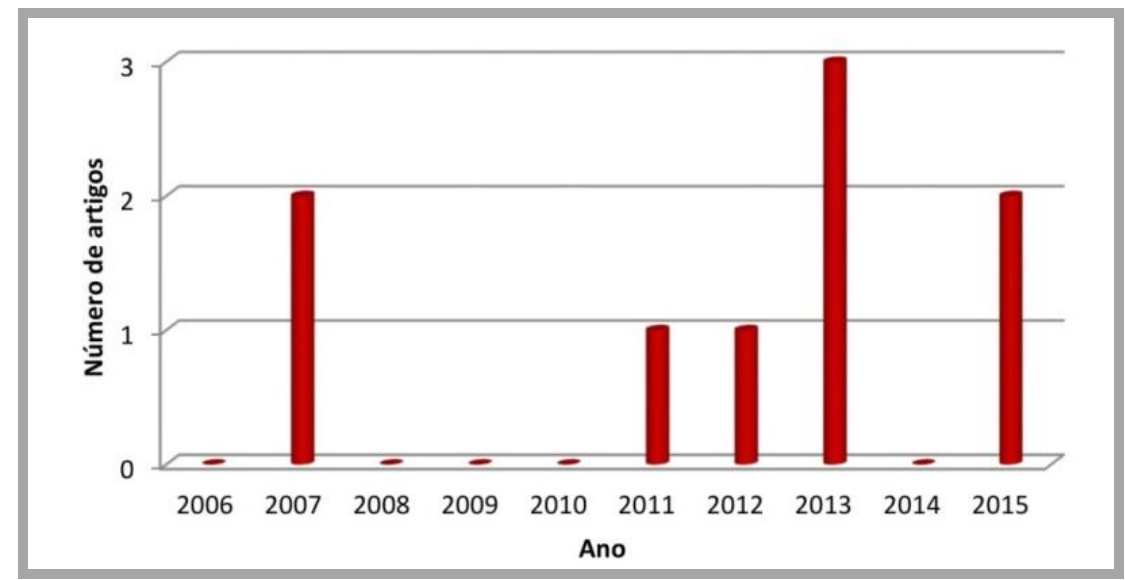

Fonte: Elaborada pelos autores, dados da pesquisa, 2016. 
O Quadro 2 a seguir apresenta a relação dos artigos selecionados para o estudo e inclui os objetivos anunciados em cada um, bem como a autoria desses artigos.

Quadro 2 - Relação dos artigos, autoria e objetivo do estudo.

\begin{tabular}{|c|c|c|}
\hline Artigo & Autor(res) & Objetivo do estudo \\
\hline $\begin{array}{l}\text { As emoções nas interações e } \\
\text { a aprendizagem significativa }\end{array}$ & $\begin{array}{l}\text { Flávia Maria Teixeira } \\
\text { dos Santos. }\end{array}$ & $\begin{array}{l}\text { "Aprofundar a discussão relativa a esta interdependência } \\
\text { entre emoção e aprendizagem, procurando contribuir para a } \\
\text { efetiva consideração da vertente afetiva na análise do } \\
\text { processo de elaboração conceitual e aprendizagem } \\
\text { significativa do sujeito" }(2007, \text { p. } 174-175) \text {. }\end{array}$ \\
\hline $\begin{array}{l}\text { Um estudo sobre as emoções } \\
\text { no contexto das interações } \\
\text { sociais em sala de aula }\end{array}$ & $\begin{array}{l}\text { Isabel Cristina de } \\
\text { Castro Monteiro; } \\
\text { Alberto Gaspar. }\end{array}$ & $\begin{array}{l}\text { "Procuramos, a partir das indicações da teoria de Vigotski, } \\
\text { estudar as interações sociais bem como as emoções } \\
\text { desencadeadas nesse processo, estabelecidas por uma } \\
\text { professora e seus alunos no contexto de aulas de Física do } \\
\text { ensino médio, envolvendo o conceito de equilíbrio de ponto } \\
\text { material e de corpo extenso" ( } 2007, \text { p. } 71) \text {. }\end{array}$ \\
\hline $\begin{array}{l}\text { Discursos Epistemológicos } \\
\text { de Afetividade como } \\
\text { Princípios de Racionalidade } \\
\text { para a Educação Científica e } \\
\text { Matemática }\end{array}$ & $\begin{array}{l}\text { Rogério Gonçalves } \\
\text { Souza; Sandra Nazaré } \\
\text { Dias Bastos. }\end{array}$ & $\begin{array}{l}\text { "Compreensão e o estudo do papel da afetividade no processo } \\
\text { de cognição, sob uma perspectiva voltada para valorização de } \\
\text { aspectos indissociáveis do sujeito epistêmico, admitindo que } \\
\text { este se constrói e constrói conhecimento em diversos } \\
\text { domínios de raciocínio, inclusive emocionais" (2011, p. 169). }\end{array}$ \\
\hline $\begin{array}{l}\text { A influência do discurso do } \\
\text { professor na motivação e na } \\
\text { interação social em sala de } \\
\text { aula }\end{array}$ & $\begin{array}{l}\text { Marco Aurélio } \\
\text { Alvarenga Monteiro; } \\
\text { Isabel Cristina de } \\
\text { Castro Monteiro; } \\
\text { Alberto Gaspar; } \\
\text { Alberto Villani. }\end{array}$ & $\begin{array}{l}\text { "Entender como o discurso do professor pode contribuir para } \\
\text { o bom nível de motivação do aluno durante uma aula" ( } 2012 \text {, } \\
\text { p. 997). }\end{array}$ \\
\hline $\begin{array}{l}\text { A afinidade com a Física: } \\
\text { uma análise feita com } \\
\text { estudantes da Universidade } \\
\text { Federal de Mato Grosso do } \\
\text { Sul (UFMS) }\end{array}$ & $\begin{array}{l}\text { Bruno dos Santos } \\
\text { Simões; Ana Luiza de } \\
\text { Quadros; Simoni } \\
\text { Tormöhlen Gehlen; } \\
\text { Hamilton Perez Soares } \\
\text { Corrêa; Rodolfo } \\
\text { Langhi. }\end{array}$ & $\begin{array}{l}\text { "Investigar fatores que influenciaram estudantes de Física da } \\
\text { Universidade Federal do Mato Grosso do Sul (UFMS) na } \\
\text { escolha do curso, e o papel que seus próprios professores } \\
\text { tiveram nessa escolha" (2013, p. } 67) \text {. }\end{array}$ \\
\hline $\begin{array}{l}\text { Experiências emocionais de } \\
\text { estudantes de graduação } \\
\text { como motivação para se } \\
\text { tornarem professores de } \\
\text { Física }\end{array}$ & $\begin{array}{l}\text { José Francisco } \\
\text { Custódio; Maurício } \\
\text { Pietrocola; Frederico } \\
\text { Firmo de Souza Cruz. }\end{array}$ & $\begin{array}{l}\text { "Investigamos a influência da dimensão afetiva na decisão de } \\
\text { seguir a carreira de professor de Física em acadêmicos da } \\
\text { Universidade do Estado de Santa Catarina e da Universidade } \\
\text { de São Paulo" (2013, p. 25). }\end{array}$ \\
\hline $\begin{array}{l}\text { Uma análise quantitativa da } \\
\text { motivação e estratégia de } \\
\text { estudo em Física }\end{array}$ & $\begin{array}{l}\text { Alcides Goya; José } \\
\text { Aloyseo Bzuneck; } \\
\text { Ivo Aparecido Goulart. }\end{array}$ & $\begin{array}{l}\text { "Avaliar o grau de motivação e estratégia pessoal de estudo } \\
\text { de física dos alunos do ensino médio, do curso técnico e das } \\
\text { engenharias, bem como a relação deste grau com as } \\
\text { atividades práticas de laboratório" }(2013, \text { p. } 254) \text {. }\end{array}$ \\
\hline 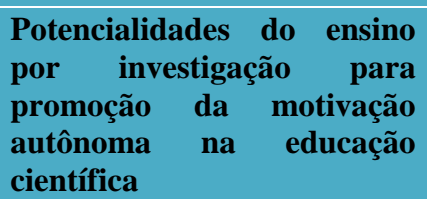 & $\begin{array}{l}\text { Luiz Clement; José } \\
\text { Francisco Custódio; } \\
\text { José de Pinho Alves } \\
\text { Filho. }\end{array}$ & $\begin{array}{l}\text { "Evidenciar como a Teoria da Autodeterminação e o Ensino } \\
\text { por Investigação podem compor uma abordagem teórica } \\
\text { consistente para subsidiar a estruturação e o encaminhamento } \\
\text { de ações de ensino-aprendizagem favoráveis á promoção da } \\
\text { motivação autônoma de estudantes" }(2015, \text { p. } 103) \text {. }\end{array}$ \\
\hline $\begin{array}{l}\text { A qualidade motivacional e } \\
\text { uso de estratégias de } \\
\text { aprendizagem no estudo de } \\
\text { Física em cursos superiores }\end{array}$ & $\begin{array}{l}\text { Alcides Goya; José } \\
\text { Aloyseo Bzuneck. }\end{array}$ & $\begin{array}{l}\text { "Objetivo avaliar a qualidade motivacional de estudantes } \\
\text { universitários e o uso que os mesmos fazem de estratégias de } \\
\text { aprendizagem na disciplina de Física" }(2015, \text { p. 519). }\end{array}$ \\
\hline
\end{tabular}

Fonte: Elaborado pelos autores, dados da pesquisa, 2016. 
A discussão dos dados apresentados nas tabelas e no gráfico está associada às categorias selecionadas para o estudo e apresentada na continuidade.

\section{Resultados}

A organização em categorias segue o proposto por Bardin (2004) que infere que as categorias são rubricas ou classes, as quais reúnem um grupo sob um título genérico, agrupamento efetuado em razão dos caracteres comuns destes elementos. Tais categorias que podem seguir um modelo aberto (emergir da própria leitura do material), modelo fechado (categorias a priori) ou modelo misto (definir a priori, mas realizar ajustes em função da análise dos dados), devem organizar os dados de modo a fornecer uma ideia clara e concisa desses dados. Dessa forma, as categorias elencadas para o presente estudo são do tipo modelo fechado, tendo como base as componentes da dimensão afetividade anunciadas por Lafortune e Saint-Pierre (1995, 1996). A essas componentes optou-se por incluir a categoria "Afetividade" referindo-se a estudos que abordam essa temática de modo geral, sem se aprofundar especificamente em nenhuma das componentes afetivas.

Nesse sentido, vale destacar que a opção por discutir os resultados a partir da sua categorização mesmo que os resultados da pesquisa tenham apontado um número pequeno de artigos, decorre de que ela poderá favorecer a compreensão e análise desses dados.

O Quadro 3 apresenta as categorias elencadas para o estudo, acompanhada da quantidade de artigos envolvido em cada categoria.

Quadro 3 - Categorias elencadas frente as componentes da dimensão afetiva

\begin{tabular}{|l|c|}
\hline \multicolumn{1}{|c|}{ Componentes } & Número de artigos \\
\hline Afetividade & 2 \\
\hline Atitude & -- \\
\hline Atribuição & -- \\
\hline Confiança em si mesmo & -- \\
\hline Emoções & 3 \\
\hline Motivação & 4 \\
\hline
\end{tabular}

Fonte: Elaborado pelos autores, dados da pesquisa, 2016. 


\section{Afetividade}

Nessa categoria apresentam-se os dois artigos envolvendo afetividade e que não abordam especificamente nenhuma das componentes afetivas. Um dos trabalhos, o escrito por Sousa e Bastos (2011), aborda a compreensão e o estudo do papel da afetividade no processo cognitivo. Docentes e doutorandos de Ciências/Matemática foram convidados a relatar uma situação em que vivenciaram a influência da afetividade na aprendizagem dos alunos. Os autores, na análise das histórias, destacaram os termos que consideraram indicadores de afetividade, e a partir dos textos, buscaram evidenciar discursos epistemológicos e configurá-los como princípios da racionalidade. Os indicadores de afetividade que se fazem presente na discussão das histórias e que influenciam a aprendizagem são: referência afetiva, relação de confiança, criar uma necessidade de aprendizagem, indícios afetivos positivos e negativos, sentimentos de fundo e estratégia de conquista. Os autores formularam 11 princípios de racionalidade para a Educação Científica e Matemática, sendo o princípio básico sobre o qual os demais derivariam: “o de que nem a afetividade nem a inteligência se desenvolvem uma à margem da outra, mas conjuntamente, numa relação de filiação" (p. 179). Segundo os autores, os relatos mostraram que "uma resposta emocional positiva leva a um novo 'processamento' de informações e conhecimentos, modelos culturais ou exemplos de comportamento também reforçam condutas, o que nos leva a crer que naturalmente ensinamos e aprendemos com nossa afetividade" (p. 182).

No segundo artigo dessa categoria, Simões et al. (2013) descrevem um estudo sobre os fatores que influenciaram estudantes da Universidade Federal do Mato Grosso do Sul (UFMS) na escolha do curso de Física e o papel que tiveram seus próprios professores nessa escolha. Visando atingir os objetivos traçados, foi construído e aplicado um questionário a graduandos do curso de licenciatura e bacharelado de Física. Dentre os resultados, os autores destacam que a afinidade com a Física foi desenvolvida antes da escolha da carreira. Os professores que foram mais lembrados pertenciam à área de Ciências Exatas, evidenciando a existência de um vínculo entre desses alunos com os professores dessa área. O modo que o professor ensina foi considerado mais importante para os alunos do que o domínio dos conteúdos. No quesito motivo que os levaram a escolha do curso, os dados indicam que, em ordem decrescente de importância, aparece a afinidade com a Física, o mercado de trabalho, a influência do professor, a influência da família e amigos, e a localização da universidade. Os autores acreditam que a afinidade com o 
conteúdo, aspecto considerado pelos alunos como o de maior importância, seja fruto do trabalho dos professores dessa disciplina, inferindo, portanto, que esses exercem influência, mesmo que indireta, na opção dos estudantes pela escolha da carreira. Nesse sentido, cabe ao professor o papel de potencializar a motivação pelas ciências em seus alunos. Segundo os autores, "os resultados obtidos em nosso trabalho confirmam a importância de um ambiente afetivo em sala de aula para que os estudantes desenvolvam interesse pelo componente curricular trabalhado. Podemos inferir que esse ambiente afetivo é importante para a aprendizagem” (p. 75).

\section{Emoções}

Nessa categoria foram encontrados três artigos relativos às emoções desencadeadas em sala de aula. O primeiro trabalho, de autoria de Monteiro e Gaspar (2007), teve o intuito de compreender os processos interativos que se estabelecem em sala de aula. $\mathrm{O}$ enfoque dado foi o de entender como o professor pode desencadear e sustentar interações sociais, com e entre seus alunos, para que o fazer pedagógico possa ser realmente significativo. Foram gravadas e analisadas aulas em que foram realizadas atividades de demonstração, atividades experimentais e aulas expositivas. Ao final de cada aula, os autores assistiram ao vídeo e fizeram anotações a respeito das suas impressões sobre a aula e identificaram as emoções que, segundo a percepção dos autores, os alunos demonstraram. A análise das aulas possibilitou perceber a importância que as emoções do professor exercem sobre as interações sociais saudáveis para o ensino e aprendizagem.

O segundo artigo dessa categoria, desenvolvido por Santos (2007), pretendeu explicitar a vertente emocional na aprendizagem significativa. As inter-relações entre significação e afetividade foram aprofundadas articulando a teoria educacional de Novak à abordagem neurobiológica de António Damásio. Para Novak, o evento educativo é acompanhado de uma experiência afetiva. Exemplo disso é que, para o autor, o estudante apresentar uma predisposição para aprender é uma das condições para a aprendizagem significativa. Para Damásio, a redução seletiva da emoção é tão prejudicial para a racionalidade quanto a emoção excessiva, sendo provável que a emoção auxilie o raciocínio. A estreita relação entre cognição e emoção refere-se tanto às emoções básicas quanto aos sentimentos de fundo e aos humores, que contribuem ou funcionam como obstáculo para a adoção de atitudes e posicionamentos nas aulas. 
O terceiro estudo, desenvolvido por Custódio, Pietrocola e Cruz (2013), investiga a influência da dimensão afetiva na decisão de seguir a carreira de professor de Física em acadêmicos da Universidade do Estado de Santa Catarina e da Universidade de São Paulo. Para tanto, foi aplicado um questionário, composto por três questões, a licenciandos em Física das duas universidades. Os dados foram analisados em um processo caracterizado por duas fases: identificar as cargas afetivas relacionadas com a escolha da carreira; descrição e análise das experiências emocionais dos estudantes segundo duas categorias (experiência emocional positiva e experiência emocional do interesse). A análise dos dados evidenciou a influência exercida pelas experiências emocionais positivas e do interesse dos estudantes na motivação para se tornarem professores de Física. No entanto, as experiências emocionais são, por natureza, passageiras. A explicação de como as experiências emocionais positivas e do interesse, momentâneas, influenciaram no desenvolvimento de interesse duradouro nos indivíduos pesquisados foi feita com base no modelo atribuição-expectativa de Silvia (2006).

\section{Motivação}

Nessa categoria, foram encontrados quatro trabalhos que apresentam a motivação em sala de aula, vista por diferentes aspectos. O primeiro artigo dessa categoria descreve um trabalho desenvolvido por Monteiro et al. (2012), com o objetivo de compreender como o discurso do professor pode contribuir para o bom nível de motivação do aluno durante a aula. Para tanto, foi realizada uma investigação sobre as interações sociais desenvolvidas numa atividade de demonstração que abordava conceitos relativos ao Princípio da Conservação da Energia. O processo de interação durante a atividade foi gravado, transcrito e analisado. O professor, após assistir ao vídeo da aula e ler as transcrições, selecionou alguns trechos e identificou as emoções demonstradas pelos alunos durante o processo de interação. Aos alunos foi mostrado o vídeo da aula, completo e depois os trechos selecionados, para que destacassem suas impressões. A análise dos dados ocorreu da seguinte forma: primeiramente foi caracterizada a interação social a partir dos constructos de Wertsch, visando avaliar se a mesma se estabeleceu dentro da zona de desenvolvimento proximal dos alunos; na sequência o discurso do professor foi categorizado, com o objetivo de identificar os principais movimentos discursivos adotados; e por último, foram apresentados os episódios selecionados, a impressão do professor e a dos alunos, sobre as 
emoções desencadeadas no processo de interação. Essa aula possibilitou emoções favoráveis à aprendizagem, ressaltando a importância da abordagem discursiva dos professores para manter o processo de motivação entre os alunos.

A segunda pesquisa dessa categoria, desenvolvida por Goya, Bzuneck e Goulart (2013), buscou avaliar o grau de motivação e estratégia pessoal de estudo de Física dos alunos do ensino médio, do curso técnico e das engenharias, assim como a influência das atividades de laboratório nesses graus. A motivação à meta de realização aprender física e a estratégia pessoal de estudo de física foram avaliadas por meio de questionários em escala Likert. Foram comparados os resultados obtidos entre o início e o final do primeiro ano dos três cursos, e também com o grupo controle de cada curso. Em todas as turmas o grau de estratégias pessoais de estudo foram maiores que a meta de realização aprender física. Os calouros do curso técnico e das engenharias obtiveram, no início do ano, os maiores índices nas duas variáveis avaliadas, no entanto, no final do ano revelaram uma queda em ambas as variáveis. Os alunos do ensino médio, por sua vez, apresentaram um aumento na motivação, mas não na estratégia. Segundo os autores, "a evolução do grau de motivação e estratégia em função da utilização de algumas atividades experimentais ficou mais clara nos resultados apresentados pelos alunos do ensino médio, uma vez que eles não tiveram outras atividades experimentais" (p. 263). Ressalta-se que estratégias eficazes de estudo promovem um melhor aprendizado.

O terceiro trabalho, de autoria de Clement, Custódio e Alves Filho (2015), objetivou promover a motivação autônoma do estudante através da abordagem teórica da Teoria da Autodeterminação relacionada com o Ensino por Investigação. A teoria da autodeterminação tem como um dos pressupostos a compreensão do envolvimento dos indivíduos, em suas atividades, sob o foco de três necessidades básicas: de autonomia, de competência e de pertencimento. Os autores ressaltam três características do ensino por investigação (importância das situaçõesproblema; aprendizagens de ciência e sobre ciência; participação ativa dos estudantes), a partir das quais traçam um caminho para a formação de comportamentos de maior grau de autorregulação, evidenciando como alguns dos marcadores da motivação intrínseca podem ser trabalhados. A presença desses elementos durante a aula promove a satisfação das necessidades de autonomia, de competência e de pertencimento; favorecendo uma maior autodeterminação dos estudantes. 
O quarto artigo, escrito por Goya e Bzuneck (2015), enquadrado nessa categoria, estuda em que medida a motivação por metas de realização tem impacto diferenciado sobre a adoção de estratégias de aprendizagem na disciplina de Física nos cursos de Licenciatura em Química e Engenharia Ambiental. O artigo assinala: que os acadêmicos de ambos os cursos apresentaram escores relativamente altos na meta domínio, mantidos estáveis entre os que continuaram até o final do semestre letivo; que a desmotivação e desistência da disciplina tenham provável origem na percepção da carga excessiva de trabalho, no fato de muitos alunos trabalharem no turno inverso e na ausência de uma estrutura cognitiva prévia bem estabelecida. Os resultados do estudo apontam para a "relevância da qualidade da motivação para que ocorra um engajamento produtivo nas atividades de aprendizagem, pela adoção de estratégias eficazes” (p. 529), sendo que o envolvimento produtivo dos alunos sofre influência direta do professor. Importante destacar que uma aprendizagem de melhor qualidade está diretamente relacionada com a adoção de estratégias eficazes de estudo.

\section{Discussão dos resultados}

A análise dos dados possibilitou observar que a utilização do tema afetividade nas pesquisas é pequena, representando, aproximadamente, 0,26\% do total de artigos investigado, conforme indicado no Quadro 1. Ao classificar os artigos identificados em relação às componentes da dimensão afetiva, conforme o proposto por Lafortune e Saint-Pierre (1995, 1996), fica evidente que a motivação e as emoções são as componentes mais pesquisadas, enquanto as atitudes, a atribuição e a confiança em si mesmo não foram abordadas em nenhum dos nove artigos. Outro aspecto identificado foi de que a produção relacionada à afetividade se concentra na temática ensino e aprendizagem, na qual constam seis artigos. Outro aspecto a ser considerado é que a única revista em que foi encontrado mais de um artigo relacionado ao tema foi a Ensaio: Pesquisa em Educação em Ciências.

Disto posto infere-se que a produção científica nacional revela que a temática vem sendo timidamente inserida nas pesquisas, apontando para a importância de considerar no ensino de Física a complexa relação entre aprendizagem e afetividade. Assim, as pesquisas concordam que "nem a afetividade nem a inteligência se desenvolvem uma à margem da outra, mas conjuntamente, numa relação de filiação" (SOUSA; BASTOS, 2011, p. 179), ressaltando a 
importância do professor nas interações sociais saudáveis, na motivação dos alunos, no envolvimento produtivo dos estudantes e na escolha da carreira. Os artigos pesquisados indicam que os professores que conseguem criar um elo afetivo com seus alunos propiciam um ambiente afetivo favorável à aprendizagem, possibilitando maior sucesso na aprendizagem dos alunos. Assim, cabe ao professor o papel de mediador da inter-relação entre afeto e cognição.

E, ainda, os estudos, mesmo que em número reduzido, apontam que a consideração da dimensão afetiva no sistema educacional é pertinente, ao inferir que o "ambiente afetivo é importante para a aprendizagem" (SIMÕES et al., 2013, p. 75) e que "ensinamos e aprendemos com nossa afetividade" (SOUSA; BASTOS, 2011, p. 182), evidenciando assim a importância dessa dimensão para a aprendizagem em Física/Ciências. Portanto, registra-se a necessidade de se considerar a influência dos aspectos afetivos em sala de aula para a implementação de ações tragam melhoria no rendimento acadêmico através do desenvolvimento de atitudes favoráveis, atribuições realistas, da confiança do aluno em relação à disciplina, de emoções que auxiliem o raciocínio e de motivações para aprender.

\section{Considerações finais}

O estudo elucidou que a temática efetividade revela-se como indicativo de potencialidade e qualificação do processo de aprendizagem em Física. A partir dessa óptica é necessário investir em estudos como forma de proporcionar a sua inserção no contexto escolar.

Por fim, conclui-se o estudo apresentando possíveis continuações do estudo, a partir de questões que surgiram do mesmo. Inicialmente menciona-se a possibilidade de desenvolver investigações envolvendo as componentes atitude, atribuição e confiança em si mesmo, avaliando a influência dessa dimensão na aprendizagem em Física; outro aspecto que emerge como potencialidade de investigações refere-se à análise da produção internacional na temática e o confronto com a nacional realizada nesse estudo. Dessa forma, percebe-se que o estudo apresentado não se esgota em si mesmo, mas abre possibilidade de desenvolver novas investigações que ancoradas na aqui desenvolvida poderá construir um arcabouço de estudos voltados a potencialidades ofertadas pela dimensão afetiva na aprendizagem em Física. 


\section{Referências}

BARDIN, Laurence. A análise de conteúdo. 3. ed. Lisboa: Edições 70, 2004.

BESSA, Valéria da Hora. Teorias da aprendizagem. Curitiba: IESDE Brasil, 2008.

BRASIL. Ministério da Educação. Secretaria de Educação Média e Tecnológica. PCN+ ensino médio: ciências da natureza, matemática e suas tecnologias: orientações educacionais complementares aos Parâmetros Curriculares Nacionais. Brasília: MEC, 2002.

CLEMENT, Luiz; CUSTÓDIO, José Francisco; ALVES FILHO, José de Pinho. Potencialidades do ensino por investigação para promoção da motivação autônoma na educação científica. Alexandria, Florianópolis, v. 8, n. 1, p. 101-129, maio 2015.

CUSTÓDIO, José Francisco; PIETROCOLA, Maurício; CRUZ, Frederico Firmo de Souza. Experiências emocionais de estudantes de graduação como motivação para se tornarem professores de Física. Caderno Brasileiro de Ensino de Física, Florianópolis, v. 30, n. 1, p. 25-57, abr. 2013.

DAMÁSIO, António Rosa. O erro de Descartes: emoção razão e o cérebro humano. São Paulo: Companhia das Letras, 1996.

DAMÁSIO, António Rosa. O mistério da consciência: do corpo e das emoções do conhecimento em si. São Paulo: Companhia das Letras, 2000.

FERREIRA, Gabriela Kaiana. Investigando a influencia do domínio afetivo em atividades didáticas de resolução de problemas de Física no Ensino Médio. 2012. Dissertação (Mestrado em Educação Científica e Tecnológica) - Universidade Federal de Santa Catarina, Florianópolis, 2012.

GIL, Antônio Carlos. Como elaborar projetos de pesquisa. 5. ed. São Paulo: Atlas, 2010.

GIL, Antônio Carlos. Métodos e técnicas de pesquisa social. 4. ed. São Paulo: Atlas, 1994.

GÓMEZ CHACÓN, Inés M. Matemática emocional: os afetos na aprendizagem matemática. Porto Alegre: ArtMed, 2003.

GOYA, Alcides; BZUNECK, José Aloyseo. A qualidade motivacional e uso de estratégias de aprendizagem no estudo de Física em cursos superiores. Revista Brasileira de Pesquisa em Educação em Ciências, Belo Horizonte, v. 15, n. 3, p. 519-535, set./dez. 2015.

GOYA, Alcides; BZUNECK, José Aloyseo; GOULART, Ivo Aparecido. Uma análise quantitativa da motivação e estratégia de estudo em física. Revista Brasileira de Ensino de Ciência e Tecnologia, Curitiba, v. 6, n. 2, maio/ago. 2013.

KLEIMAN, Ângela B.; MORAES; Silvia E. Leitura e interdisciplinaridade: tecendo redes nos projetos da escola. Campinas: Mercado das Letras, 1999.

LAFORTUNE, Louise; SAINT-PIERRE, Lise. A afectividade e a metacognição na sala de aula. Lisboa: Instituto Piaget, 1996.

LAFORTUNE, Louise; SAINT-PIERRE, Lise. Intervenir sur la métacognition et l'affectivité. Pédagogie collégiale, Québec, Canadá, v. 8, n. 4, p. 16-22, maio 1995.

LEGENDRE, Renald. Dictionnaire actuel de l'éducation. Montréal: Guérin, 1993.

MARTIN, Barbara L.; BRIGGS, Leslie J. The affective and cognitive domains: integration for instruction and research. NJ: Educational Technology, 1986. 
MAURINA, Keli C. Estudo das expectativas de estudantes do ensino fundamental e médio sobre a disciplina de Física. 2008. Dissertação (Mestrado em Educação Científica e Tecnológica) - Universidade Federal de Santa Catarina, Florianópolis, 2008.

MONTEIRO, Marco Aurélio Alvarenga et al. A influência do discurso do professor na motivação e na interação social em sala de aula. Ciência \& Educação, Bauru, v. 18, n. 4, p. 997-1010, 2012.

MONTEIRO, Isabel Cristina de Castro; GASPAR, Alberto. Um estudo sobre as emoções no contexto das interações sociais em sala de aula. Investigações em Ensino de Ciências, Porto Alegre, v. 12, n. 1, p. 7184, mar. 2007.

PINHEIRO, Terezinha de Fátima. Sentimento de realidade, afetividade e cognição no ensino de ciências. 2003. Tese (Doutorado em Educação Científica e Tecnológica) - Programa de Pós-Graduação em Educação Científica e Tecnológica, Universidade Federal de Santa Catarina, Florianópolis, 2003.

PINTO, Heloysa Dantas de Souza. Emoção e ação pedagógica na infância: contribuição de Wallon. Temas em Psicologia, Ribeirão Preto, v. 1, n. 3, p. 73-76, 1993.

REZENDE, Flavia; OSTERMANN, Fernanda. A prática do professor e a pesquisa em ensino de Física: novos elementos para repensar essa relação. Caderno Brasileiro de Ensino de Física, Florianópolis, v. 22, n. 3, p. 316-337, dez. 2005.

ROMANOWSKI, Joana Paulin. As licenciaturas no Brasil: um balanço das teses e dissertações dos anos 90. 2002. Tese (Doutorado) - Faculdade de Educação, Universidade de São Paulo, São Paulo, 2002.

SACKS, Oliver. Um antropólogo em marte: sete histórias paradoxais. São Paulo: Companhia das letras, 1995.

SANTOS, Flávia Maria Teixeira dos. As emoções nas interações e a aprendizagem significativa. Ensaio: Pesquisa em Educação em Ciências, Belo Horizonte, v. 9, n. 2, p. 173-187, jul./dez. 2007.

SANTOS, Flávia Maria Teixeira dos. Do ensino de ciências como mudança conceitual à fronteira de uma abordagem afetiva. 1996. Dissertação (Mestrado em Educação) - Universidade Federal de Santa Catarina, Florianópolis, 1996.

SILLAMY, Norbert. Dictionnaire encyclopédique de psychologie. Paris: Bordas, 1980.

SILVIA, Paul J. Exploring the psychology of interest. New York: Oxford University Press, 2006.

SIMÕES, Bruno dos Santos et al. A afinidade com a Física: uma análise feita com estudantes da Universidade Federal de Mato Grosso do Sul (UFMS). Ensaio, Belo Horizonte, v. 15, n. 1, p. 67-80, jan./abr.2013.

SOUSA, Rogério Gonçalves; BASTOS, Sandra Nazaré Dias. Discursos epistemológicos de afetividade como princípios de racionalidade para a educação científica e matemática. Ensaio, Belo Horizonte, v. 13, n. 3, p. 169-184, set./dez. 2011.

VYGOTSKY, Lev Semenovitch. Pensamento e linguagem. São Paulo: Martins Fontes, 1995.

WALLON, Henri. Les origines du caractère chez l'enfant. Paris: P.U.F., 1949. 
Cleci Teresinha Werner da Rosa - Universidade de Passo Fundo. Passo Fundo | RS | Brasil. Contato: cwerner@upf.br

Luiz Marcelo Darroz - Universidade de Passo Fundo. Passo Fundo | RS | Brasil. Contato: 1darroz@upf.br

Ana Claudia Tasso dos Santos - Universidade de Passo Fundo. Passo Fundo | RS | Brasil. Contato: anacts_@hotmail.com

Artigo recebido em: 16 jan. 2017 e aprovado em: 31 ago. 2017. 